\title{
Analysis of the antibiotic prophylaxis prescribed by Spanish Oral Surgeons
}

\author{
Manuel Sancho-Puchades ${ }^{1}$, José-María Herráez-Vilas ${ }^{2}$, Eduardo Valmaseda-Castellón ${ }^{3}$, Leonardo Berini- \\ Aytés $^{4}$, Cosme Gay-Escoda ${ }^{5}$
}

\footnotetext{
${ }^{1}$ Resident of the Master of Oral Surgery and Implantology. University of Barcelona Dental School

${ }^{2}$ Associate Professor of Oral Surgery. Professor of the Master of Oral Surgery and Implantology. University of Barcelona Dental School. Investigator of the UB-IDIBELL Institute

${ }^{3}$ Assistant Profesor of Oral Surgery. Professor of the Master of Oral Surgery and Implantology. University of Barcelona Dental School. Investigator of the UB-IDIBELL Institute

${ }^{4}$ Assistant Professor of Oral Surgery. Subdirector of the Master of Oral Surgery and Implantology. Dean of the University of Barcelona Dental School. Investigator of the UB-IDIBELL Institute

${ }^{5}$ Chairman of Oral and Maxillofacial Surgery. Director of the Master of Oral Surgery and Implantology. University of Barcelona Dental School. Investigator of the UB-IDIBELL Institute. Maxillofacial surgeon of the Teknon Medical Center, Barcelona (Spain)
}

Correspondence:

Centro Médico Teknon

Instituto de Investigación UB-IDIBELL Sancho-Puchades M, Herráez-Vilas JM, Valmaseda-Castellón E, Berini-

C/Vilana 12

08022 - Barcelona (Spain)

cgay@ub.edu

Aytés L, Gay-Escoda C. Analysis of the antibiotic prophylaxis prescribed by Spanish Oral Surgeons. Med Oral Patol Oral Cir Bucal. 2009 Oct 1;14 (10):e533-7.

http://www.medicinaoral.com/medoralfree01/v14i10/medoralv14i10p533.pdf

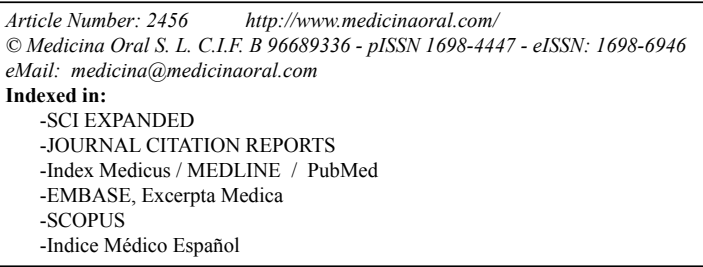

\begin{abstract}
Aim: To identify prophylactic antibiotic prescription practices among Spanish dentists with preferential dedication to Oral Surgery in different types of tooth extraction surgeries.

Method: Members of the Spanish Oral Surgery Society were surveyed on antibiotic prophylaxis use in 4 different tooth extraction modalities scaled according to their surgical invasiveness.

Results: Sixty-nine of the 105 distributed questionnaires were returned completed. Thirteen percent of the surveyed surgeons would prescribe antibiotics to prevent postoperative wound infection when confronted with conventional tooth extraction lasting less than 5 minutes. In the case of surgery lasting more than 5 minutes, the percentage of participants that would prescribe antibiotics increased to $39 \%$. When a mucoperiosteal flap was elevated or an ostectomy was performed, $87 \%$ and $100 \%$, respectively, would prescribe antibiotic prophylaxis. Amoxicillin and its combination with clavulanic acid were the most commonly prescribed antibiotics. All participants would prescribe the antibiotic orally, starting after surgery and with a duration that ranged from 2-8 days. Conclusions: The results obtained suggest that antibiotic prophylaxis for preventing local odontogenic infection is not being correctly implemented in Spain. This can generate new bacterial resistances, facilitate adverse drug reactions and favor opportunistic infections. Better designed studies are needed in order to clarify the role of antibiotics in the prevention of postsurgical wound infection.
\end{abstract}

Key words: Antibiotic prophylaxis, oral surgery, local infection. 


\section{Introduction}

The administration of antibiotics to treat established infections or to prevent distant infections in risk patients is a broadly accepted procedure. However, the systematic use of antibiotic prophylaxis in patients with no individual risk factors is a controversial issue lacking a scientific basis.

Spain is one of the European countries with the highest antibiotic consumption rate and, therefore, with the highest percentages of bacterial resistance (1). This increased consumption rate is not justified by a greater prevalence of susceptible infections in this country compared to others; rather, there is a tendency to prescribe antibiotics against any infection, regardless of the underlying etiology. Although a medical prescription is required by law in order to purchase antibiotics in Spain, 30\% of all antibiotic consumption is made without a prescription (2). In a recently published survey involving 19 European countries, Spain stands out as one of the countries with the highest self-medication index, along with Lithuania and Romania. Similarly, it is also one of the countries where more antibiotics are stored in homes (3).

As health professionals, dentists may be contributing to this antibiotic abuse by prescribing antimicrobial prophylaxis and treatments that are not always scientifically warranted. Ten percent of global antibiotic prescription in Spain is made by dentists, sometimes for the treatment of odontogenic infections, but mostly for prophylactic reasons in surgeries and other dental procedures (3). However, systematic antibiotic prescription cannot be considered an acceptable practice. In numerous circumstances the infection threat is so low that the risks derived from antibiotic usage exceed their potential benefits (4-7). Besides, in many cases, prescriptions are not ideal considering the bacterial spectrum involved, the treatment duration, timing or administration route. In an attempt to solve this problem, consensus antibiotic prescription protocols have been developed in this country (8). However, in daily practice, the number of clinicians that adhere to these protocols is limited, and an enormous variety of pharmacological guidelines for a single indication can be found.

The aim of this paper is to identify prophylactic antibiotic prescription practices among Spanish dentists with preferential dedication to Oral Surgery in different types of dental extraction surgeries.

\section{Material and methods}

During the IV Symposium of the Spanish Oral Surgery Society held in 2006, members were randomly surveyed about antibiotic prophylaxis to prevent postoperative wound infection. One hundred and five questionnaires were delivered to the audience of the inaugural conference of the Symposium. The only participation require- ment was Spanish Oral Surgery Society membership. The survey considered four tooth extraction modalities scaled according to their surgical invasiveness. These modalities were as follows: 1) conventional tooth extraction performed in less than 5 minutes; 2) conventional tooth extraction lasting more than 5 minutes; 3) surgical tooth extraction without ostectomy; and 4) surgical tooth extraction with ostectomy. The term "conventional tooth extraction" refers to tooth extraction that does not require flap elevation, while "surgical tooth extraction" means that a mucoperiosteal flap must be raised. All scenarios referred to patients free of any systemic disease or signs of infection at the surgical site during the procedure. Every participant was asked to indicate the antibiotic dose, prescription guideline, and treatment duration. In addition, the second line antibiotic chosen in case of allergy to the first antibiotic was also requested. The questionnaire was anonymous; the only personal data required was age, years of professional practice, and the city or location of practice, in an attempt to establish possible prescription patterns among groups.

A database was created for further analysis using version 15.0 of the Statistical Package for Social Sciences (SPSS, SPSS inc., Chicago, IL, USA). Data description was carried out by frequency tables. When obtaining the numerical representation by percentages, the total number of answers for each query was taken into account. Each collected questionnaire was included in the study, even if not every section was completed. A Chi-squared test was used to assess the association between antibiotic prescription and age $(\geq 30$ years and $<30$ years), years of professional practice ( $\geq 6$ years and $<6$ years) and city of professional practice (Barcelona, Cáceres, Santiago de Compostela, Córdoba, Madrid, Pamplona, Seville, Valencia). Statistically significant differences were considered for $\mathrm{p}<0.05$.

\section{Results}

Sixty-nine of the 105 delivered questionnaires were completed, representing a $65.7 \%$ response rate. The second line antibiotic chosen in case of allergic patients was not specified in 33 of these 69 questionnaires.

Figures 1, 2 and 3 represent the antibiotics and administration guidelines prescribed in each scenario, represented as percentages and absolute values of answered queries.

Thirteen percent of the surveyed surgeons answered they would prescribe antibiotics to prevent local postoperative infection in conventional tooth extraction taking less than 5 minutes to be completed. Eighty-seven percent of these would choose amoxicillin, while the rest would prefer its combination with clavulanic acid. When conventional tooth extraction takes more than 5 minutes, the percentage of participants that would em- 


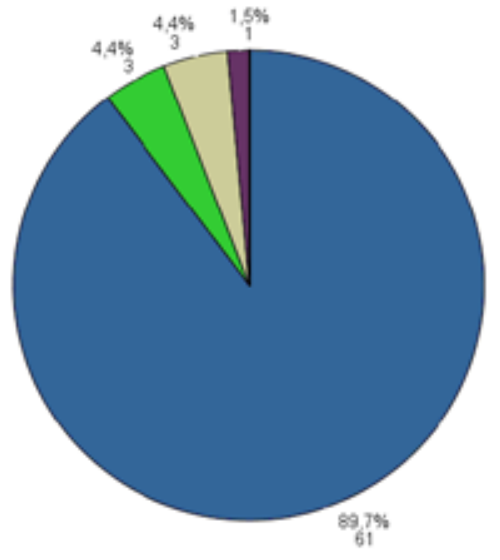

a) Conventional tooth extraction with a duration less than 5 minutes.

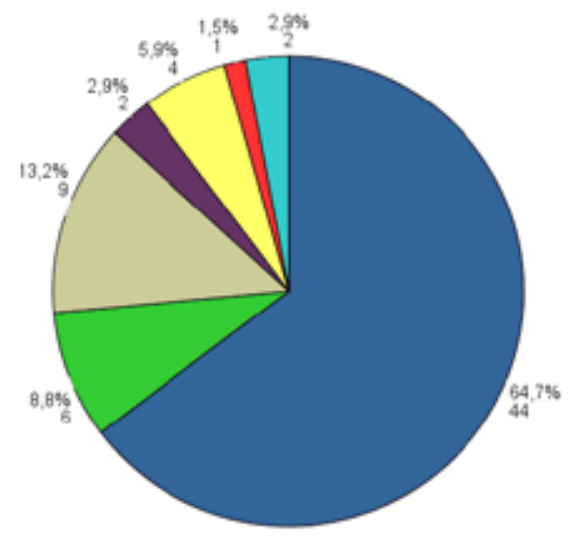

b) Comventional tooth extraction with a duration more than 5 minutes.
Absence of antibiotic

prescription.

Amoxcilin 500m, $1 / 8 \mathrm{~h}$

$\square$ Amoxicilin $750 \mathrm{mg}, 1 / 8 \mathrm{~h}$

AmoxicilinvClandanic Acid

$500 \mathrm{mg}-125 \mathrm{mg} .1 / 8 \mathrm{~h}$

7 AvnoxicilinvClandaric Acid $\square_{875 \mathrm{mg}-125 \mathrm{mg} .1 / 8 \mathrm{~h}}^{\text {Aun }}$

Amoxicilin/Clandanic acid

$1000 \mathrm{ng}$ - $25 \mathrm{Tm}$. 1/8

$\square$ Ampicillin $75 \mathrm{cmg}, 1 / 8 \mathrm{~h}$

$\square$ Lincomicine $500 \mathrm{mg}$. $1 / 8 \mathrm{~h}$

Fig. 1. Conventional extraction (Data presented as percentage (\%) and absolute value of answered questions).

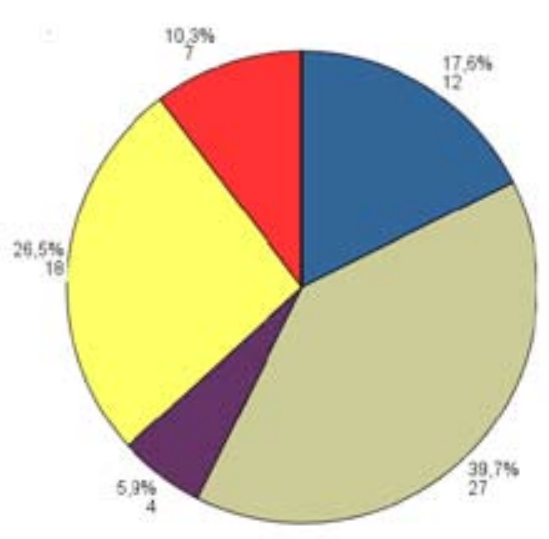

a) Surgical tooth extraction without ostectomy.

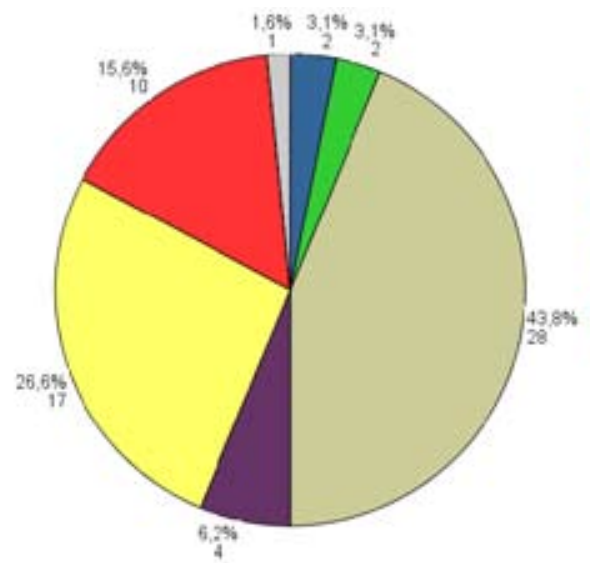

b) Surgical tooth extraction with ostectomy.
Absence of arbbictc prescription.

Amoxecillin 500mg, 1/8 $\mathrm{h}$

Amoxilin 750mg, $1 / 8 \mathrm{~h}$

AmosicillinuClamulanic Acid

$500 \mathrm{mg}-125 \mathrm{mg}, 1 / 0 \mathrm{~h}$

Amoxillinclavulanic Acid

875mg-125mg. 1/8 h

Amoxicillinclavularic acid

Ampicilin $750 \mathrm{mg} .1 / 8 \mathrm{~h}$

Lincomicine $500 \mathrm{mg}$, $1 / 3 \mathrm{~h}$

Fig. 2. Surgical extraction (Data presented as percentage (\%) and absolute value of answered questions).

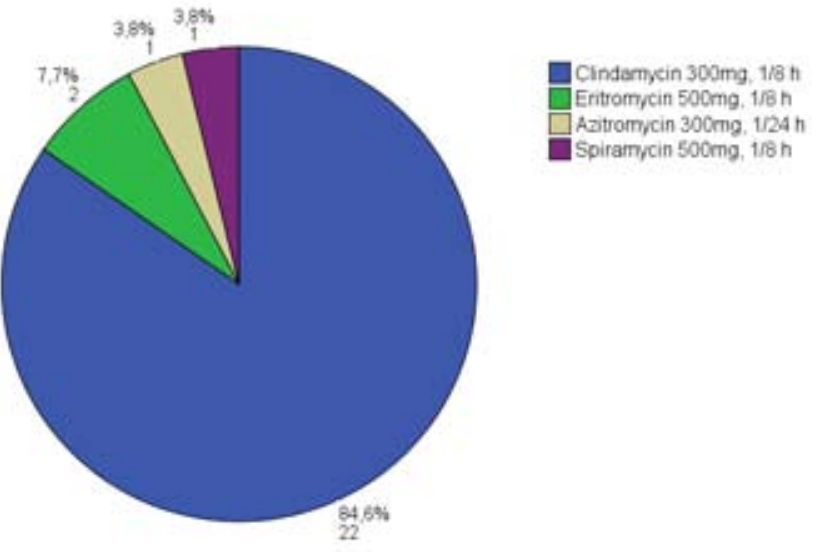

Fig. 3. Second line antibiotic in allergic patients (Data presented as percentage (\%) and absolute value of answered questions). 
ploy antibiotics increased to $39 \%$. Based on the antibiotic selected, $65 \%$ of all antibiotic prophylaxis prescribers would use amoxicillin, while $34 \%$ would use the amoxicillin-clavulanic acid combination.

Participants were also questioned about the need to administer antibiotics when a mucoperiosteal flap was elevated in order to extract the tooth. Eighty-seven percent agreed to administering antibiotic prophylaxis in this case. The percentage of clinicians that would choose amoxicillin was $51 \%$, with $48 \%$ of them opting for the amoxicillin-clavulanic acid combination. Similar results were obtained when ostectomy was performed during surgery. In this case, all clinicians considered antibiotic prophylaxis to be necessary ( $55 \%$ would choose amoxicillin and $45 \%$ amoxicillin-clavulanic acid).

Clindamycin was the most frequently chosen (93.1\%) second-line antibiotic for patients with a history of allergy to the first line antibiotic, followed by erythromycin $(7.7 \%)$ and spiramycin and azithromycin, both with a $3.4 \%$ of responses (Fig. 3).

In each case, the participants would prescribe antibiotic prophylaxis via the oral route, after surgery, and with a duration that ranged between 2 and 8 days.

No statistically significant differences were observed when considering prescription guidelines according to participant age, years of professional practice, or city of practice.

\section{Discussion}

The results of this study clearly indicate there is no consensus among clinicians regarding antibiotic therapy for preventing local infection. Disagreements are found regarding prophylactic therapy indications, ideal antibiotic selection, as well as the recommended pharmacological guidelines.

The small number of questionnaires analyzed becomes a major drawback for this study, hindering the extrapolation of its results to the entire population of Spanish dentists with preferential dedication to Oral Surgery. However, we believe that the results can be helpful for understanding the current situation of antibiotic prophylaxis prescription in this professional community. Another limitation of the study was the fact that the queries had to be brief and simple, so that the questionnaire could be rapidly read and easily completed. This implied the omission of relevant information that the clinician should consider before deciding whether antibiotic prophylaxis should be administered or not.

In any case, it is surprising that $13 \%$ of the surveyed individuals would administer antibiotics to prevent local infection in conventional tooth extraction taking less than 5 minutes. Likewise, it is alarming that the percentage increased to $39 \%$ when conventional extraction extended beyond this time. Flapless tooth extraction is a minimally invasive surgical procedure with few in- fectious risk factors. The global postoperative infection risk after lower third molar surgical removal has been estimated to be between 1-12\% (9-12), and is even smaller when other teeth are considered (13). Therefore, the routine administration of antibiotics in conventional tooth extractions in infection-free surgical fields should be contraindicated (14).

When the surgical procedure becomes more invasive, needing flap elevation or ostectomy, the percentage of clinicians that would prescribe antibiotic treatment increased considerably ( $87 \%$ and $100 \%$, respectively). This implies that flap elevation and bone removal are interpreted as infection risk factors by most of the surveyed clinicians. Several studies underscore the degree of dental impaction, and consequently the amount of bone removed during extraction, as a major risk factor for the emergence of infectious complications, and therefore a factor tributary to antibiotic prophylaxis (1517). Conversely, other clinical trials question the role of antibiotics even in these cases (4-7), equaling their efficacy to that of a placebo-controlled group. This controversy implies that not every procedure in Oral Surgery is tributary to antibiotic prophylaxis. The presence of risk factors needs to be assessed. These include intrinsic features of the surgical technique (for instance, ostectomy degree) and specific characteristics of each patient (age, smoking, systemic diseases and their repercussion upon the host immune system).

When the aforementioned infection risk factors are present and antibiotic prophylaxis is deemed necessary, drug selection as well as administration guidelines have to be strategic. $\beta$-lactam antibiotics or their combination with a $\beta$-lactamase inhibitor were the drugs selected by most clinicians. Traditionally, $\beta$-lactam antibiotics have been used as first-line therapy in odontogenic infections (18). Currently, studies suggest that their antimicrobial activity against some bacteria involved in odontogenic infection is declining due to the increasing emergence of $\beta$-lactamase producing bacteria. Consequently, some authors consider the combination of a $\beta$-lactam antibiotic with a $\beta$-lactamase inhibitor, such as amoxicillin plus clavulanic acid, to be an up-to-date first-line treatment option $(8,19-21)$. The amoxicillin-clavulanic acid combination theoretically covers the entire bacterial spectrum of odontogenic infections in Spain. However, a lack of knowledge on the pathogenesis and bacterial interrelationships leading to postextraction local infection does not allow the ruling out of the potential value of other antibiotics.

When analyzing administration strategies, the results obtained show that all clinicians would start antibiotic prophylaxis after surgery. However, this behaviour is contrary to antibiotic prophylaxis guidelines, which state that tissue antibiotic levels should be high during the actual procedure (22). In fact, numerous authors 
have shown that prophylactic administration of antibiotics in the preoperative period can significantly reduce the postoperative wound infection rate (23-26). Considering the duration of prophylaxis, the latter should be as short as possible as long as it is effective (21). Our results reveal that most clinicians would prescribe the antibiotic via the oral route, starting after surgery, and for time periods that ranged from 2 to 8 days. According to the consulted literature, when administering the antibiotic via the oral route, a single preoperative dose is sufficient. If the surgical intervention extends in time or tissue damage is considerable, another antibiotic dose can be administered at the equator of its therapeutic interval $(22,26,27)$. In any case, antibiotic prophylaxis should not exceed 24 hours; extended administration does not reduce the infection rate, increases the risk of adverse drug reactions, and facilitates the emergence of bacterial resistances $(22,26)$.

Our study reflects that antibiotic prophylaxis for local odontogenic infection is not being properly performed in Spain. Antibiotic abuse for unjustified indications leads to the emergence of increasingly resistant pathogenic bacterial strains, increases the risk of allergic and adverse drug reactions, and produces imbalances in the human endogenous flora. More clinical studies are needed to identify the infection risk factors amenable to antibiotic prophylaxis, clarify the pathogenesis of postoperative local infection, and develop effective clinical guidelines based not only on experts opinions but particularly also on scientific evidence.

\section{References}

1. Cars O, Mölstad S, Melander A. Variation in antibiotic use in the European Union. Lancet. 2001;357:1851-3.

2. Grigoryan L, Haaijer-Rysjamp FM, Burgerhof JG, Mechtler R, Deschepper R, Tambic-Andrasevic A, et al. J. Self-medication with antimicrobial drugs in Europe. Emerg Infect Dis. 2006;12:452-9.

3. Bascones Martínez A, Aguirre Urízar JM, Bermejo Fenoll A, Blanco Carrión A, Gay-Escoda C, González-Moles MA, et al. Consensus statement on antimicrobial treatment of odontogenic bacterial infections. Med Oral Patol Oral Cir Bucal. 2004;9:369-76, 363-9.

4. Zeitler DL. Prophylactic antibiotics for third molar surgery: a dissenting opinion. J Oral Maxillofac Surg. 1995;53:61-4.

5. Monaco G, Staffolani C, Gatto MR, Checchi L. Antibiotic therapy in impacted third molar surgery. Eur J Oral Sci. 1999;107:437-41.

6. MacGregor AJ. Reduction in morbidity in the surgery of the third molar removal. Dent Update. 1990;17:411-4.

7. Kuriyama T, Nakagawa K, Karasawa T, Saiki Y, Yamamoto E, Nakamura S. Past administration of beta-lactam antibiotics and increase in the emergence of beta-lactamase-producing bacteria in patients with orofacial odontogenic infections. Oral Surg Oral Med Oral Pathol Oral Radiol Endod. 2000;89:186-92.

8. Gutiérrez JL, Bagán JV, Bascones A, Llamas R, Llena J, Morales $\mathrm{A}$, et al. Consensus document on the use of antibiotic prophylaxis in dental surgery and procedures. Med Oral Patol Oral Cir Bucal. 2006;11:E188-205

9. Loukota RA. The effect of pre-operative perioral skin preparation with aqueous povidone-iodine on the incidence of infection after third molar removal. Br J Oral Maxillofac Surg. 1991;29:336-7.

10. Van Gool AV, Ten Bosch JJ, Boering G. Clinical consequences of complaints and complications after removal of the mandibular third molar. Int J Oral Surg. 1977;6:29-37.

11. Osborn TP, Frederickson G Jr, Small IA, Torgerson TS. A prospective study of complications related to mandibular third molar surgery. J Oral Maxillofac Surg. 1985;43:767-9.

12. MacGregor AJ. Aetiology of dry socket: a clinical investigation. Br J Oral Surg. 1968;6:49-58.

13. Arteagoitia I, Diez A, Barbier L, Santamaría G, Santamaría J. Efficacy of amoxicillin/clavulanic acid in preventing infectious and inflammatory complications following impacted mandibular third molar extraction. Oral Surg Oral Med Oral Pathol Oral Radiol Endod. 2005;100:e11-8.

14. Chiapasco M, De Cicco L, Marrone G. Side effects and complications associated with third molar surgery. Oral Surg Oral Med Oral Pathol. 1993;76:412-20.

15. Benediktsdóttir IS, Wenzel A, Petersen JK, Hintze H. Mandibular third molar removal: risk indicators for extended operation time, postoperative pain, and complications. Oral Surg Oral Med Oral Pathol Oral Radiol Endod. 2004;97:438-46.

16. Piecuch JF, Arzadon J, Lieblich SE. Prophylactic antibiotics for third molar surgery: a supportive opinion. J Oral Maxillofac Surg. 1995;53:53-60.

17. Curran JB, Kennett S, Young AR. An assessment of the use of prophylactic antibiotics in third molar surgery. Int J Oral Surg. 1974;3:1-6.

18. Abu Fanas SH, Drucker DB, Hull PS. Amoxycillin with clavulanic acid and tetracycline in periodontal therapy. J Dent. 1991;19:97-9. 19. Maestre-Vera JR. Treatment options in odontogenic infection. Med Oral Patol Oral Cir Bucal. 2004;9 Suppl:25-31, 19-24.

20. Todd PA, Benfield P. Amoxicillin/clavulanic acid. An update of its antibacterial activity, pharmacokinetic properties and therapeutic use. Drugs. 1990;39:264-307.

21. Peterson LJ. Antibiotic prophylaxis against wound infections in oral and maxillofacial surgery. J Oral Maxillofac Surg. 1990;48:61720.

22. Polk HC Jr, Ausobsky JR. The role of antibiotics in surgical infections. Adv Surg. 1983;16:225-75.

23. Polk HC Jr, Simpson CJ, Simmons BP, Alexander JW. Guidelines for prevention of surgical wound infection. Arch Surg. 1983;118:1213-7.

24. Stone HH, Haney BB, Kolb LD, Geheber CE, Hooper CA. Prophylactic and preventive antibiotic therapy: timing, duration and economics. Ann Surg. 1979;189:691-9.

25. Stone HH. Basic principles in the use of prophylactic antibiotics. J Antimicrob Chemother. 1984;14 Suppl B:33-7.

26. Burke JF. Preventive antibiotic management in surgery. Annu Rev Med. 1973;24:289-94.

27. Brescó-Salinas M, Costa-Riu N, Berini-Aytés L, Gay-Escoda C. Antibiotic susceptibility of the bacteria causing odontogenic infections. Med Oral Patol Oral Cir Bucal. 2006;11:E70-5.

\section{Acknowledgements}

This work has been conducted by the Buccodental and Maxillofacial Pathology Investigating Group of the UB-IDIBELL Institute with the financial support of the Oral Surgery clinical care-teaching agreement between the University of Barcelona, Consorci Sanitari Integral, and the Servei Català de la Salut of the Generalitat de Catalunya. 